\title{
Applicability of the WHO maternal near- miss tool: A nationwide surveillance study in Suriname
}

Kim JC Verschueren', Lachmi R Kodan ${ }^{1,2}$, Raëz R Paidin ${ }^{3}$, Sarah M Samijadi², Rubinah R Paidin², Marcus J Rijken ${ }^{1,4}$, Joyce L Browne ${ }^{4}$, Kitty WM Bloemenkamp ${ }^{1}$

\footnotetext{
${ }^{1}$ Department of Obstetrics, Division Women and Baby, Birth Centre Wilhelmina's Children Hospital, University Medical Center Utrecht, Utrecht University, Utrecht, the Netherlands ${ }^{2}$ Department of Obstetrics, Academica Hospital Paramaribo, Paramaribo, Suriname ${ }^{3}$ Department of Obstetrics, Diakonessen Hospital Paramaribo, Paramaribo, Suriname ${ }^{4}$ Julius Global Health, Julius Centre for Health Sciences and Primary Care, University Medical Centre Utrecht, Utrecht University, Utrecht, the Netherlands
}

Background Maternal near-miss (MNM) is an important maternal health quality-of-care indicator. To facilitate comparison between countries, the World Health Organization (WHO) developed the "MNM-tool". However, several low- and middle-income countries have proposed adaptations to prevent underreporting, ie, Namibian and Sub-Sahara African (SSA)-criteria. This study aims to assess MNM and associated factors in middle-income country Suriname by applying the three different MNM tools.

Methods A nationwide prospective population-based cohort study was conducted using the Suriname Obstetric Surveillance System (SurOSS). We included women with MNM-criteria defined by WHO-, Namibianand SSA-tools during one year (March 2017-February 2018) and used hospital births ( $86 \%$ of total) as a reference group.

Results There were 9114 hospital live births in Suriname in the one-year study period. SurOSS identified 71 women with WHO-MNM (8/1000 live births, mortality-index 12\%), 118 with Namibian-MNM (13/1000 live births, mortality-index 8\%), and 242 with SSA-MNM (27/1000 live births, mortality-index 4\%). Namibian- and SSA-tools identified all women with WHO-criteria. Blood transfusion thresholds and eclampsia explained the majority of differences in MNM prevalence. Eclampsia was not considered a WHO-MNM in $80 \%(n=35 / 44)$ of cases. Nevertheless, mortality-index for MNM with hypertensive disorders was $17 \%$ and the most frequent underlying cause of maternal deaths $(n=4 / 10,40 \%)$ and MNM ( $n=24 / 71$, $34 \%$ ). Women of advanced age and maroon ethnicity had twice the odds of WHO-MNM (respectively adjusted odds ratio $(\mathrm{aOR})=2.6,95 \%$ confidence interval $(\mathrm{CI})=1.4-4.8$ and $\mathrm{aOR}=2.0,95 \% \mathrm{CI}=1.2-3.6)$. The stillbirths rate among women with WHO-MNM was 193/1000births, with six times higher odds than women without MNM $(\mathrm{aOR}=6.8,95 \% \mathrm{CI}=3.0$ 15.8). While the prevalence and mortality-index differ between the three MNM tools, the underlying causes of and factors associated with MNM were comparable.

Conclusions The MNM ratio in Suriname is comparable to other countries in the region. The WHO-tool underestimates the prevalence of MNM (high mortality-index), while the adapted tools may overestimate MNM and compromise global comparability. Contextualized MNM-criteria per obstetric transition stage may improve comparability and reduce underreporting. While MNM studies facilitate international comparison, audit will remain necessary to identify shortfalls in quality-of-care and improve maternal outcomes.

\section{Correspondence to:}

Kim J.C. Verschueren, MD

kim.sxm@gmail.com 
Sustainable Development Goal target 3.1 aims to eliminate preventable maternal deaths and reduce the global maternal mortality ratio (MMR) to less than 70 per 100000 live births (LB) by 2030 [1]. Women who die represent just the tip of the iceberg: for each woman who dies, at least ten suffer from severe maternal complications and narrowly escape death by chance or because of the care they receive: a maternal near-miss (MNM) [2]. With the decline of maternal deaths, MNM is used as a proxy to measure the quality of obstetric care [2,3]. MNM has the advantage that it occurs more frequently and that the survival of the woman makes it less threatening to report by health care providers [2-4]. In Suriname, a middle-income country in South America, the MMR is 130 per 100000 LB, one of the highest in the Caribbean \& America's, but the absolute number of deaths is "only" ten to fifteen per year [5]. This makes MNM studies crucial to develop justified recommendations and finally reduce maternal mortality $[2,4]$.

To standardize the MNM definition and facilitate comparison between different countries, the World Health Organization (WHO) developed the "Maternal near-miss approach" in 2011 [2]. The classification includes three types of criteria: disease-, intervention,- and organ dysfunction-based. If any organ dysfunction criteria are met, the MNM approach defines the case as 'life-threatening' and therefore, MNM. The choice for organ-dysfunction criteria follows the concept that the following sequence of events leads from good health to death: clinical disease, systemic inflammatory response syndrome, organ dysfunction, organ failure and finally death [6,7]. Following this concept, organ dysfunction markers (25 criteria) define MNM [2]. However, several studies in different settings demonstrated that the organ-dysfunction criteria may not be suitable and proposed adapted criteria to prevent underreporting of life-threatening disorders [8-12]. In 2017, a Delphi study suggested adaptations to the WHO-criteria for low-resource settings in Sub-Sahara Africa (SSA) [10]. The adapted MNM tool included several clinical conditions, such as eclampsia, sepsis and uterine ruptured and a lower threshold for blood transfusion, and performed well in Ethiopia [11]. A recent study in Namibia suggested that both tools were not suitable for middle-income countries and proposed criteria 'in-between' WHO-MNM and SSA-MNM [12]. However, the resulting heterogeneity of these adapted MNM criteria compromises comparability [3], which the WHO approach specifically intended to avoid.

The goal of studying maternal near-miss in Suriname would be to (1) find a reason for the relatively high maternal mortality, and stillbirth rate in the country $[5,13,14]$, (2) compare findings to other countries and (3) improve the quality of care. Due to the variety of (adapted) MNM-criteria, it is unclear which criteria are most applicable to achieve the abovementioned aims. Therefore, this nationwide study in Suriname first aims to apply the WHO-MNM tool and adapted Namibian and SSA-tools to evaluate differences in prevalence, mortality-index, underlying causes, and factors associated with maternal near-miss. The comparison of MNM in a clinical setting may facilitate possible amendments of the global WHO nearmiss criteria to assure uniformity and applicability.

\section{METHODS}

\section{Study design and setting}

A prospective nationwide population-based cohort study, using the Suriname Obstetric Surveillance System (SurOSS), was performed during one year (March 2017 to February 2018). Suriname is situated on the Northern coast of South-America, with a population of approximately 560000 and 10000 live births a year [15]. The five hospitals conduct approximately $86 \%$ of all births, $4 \%$ women deliver at home, $6 \%$ of women deliver at the primary health care services and in $4 \%$ the place of birth is unknown [15]. In general, all women with (severe) morbidity are referred to a hospital. Maternal deaths (in facilities and the community) are reported to the Surinamese Maternal Mortality Committee. For a detailed description of the health care system, see our previous publications on maternal mortality and childbirth outcomes $[5,13,14,16]$.

\section{Maternal near-miss case definition}

Within SurOSS we identified all women with potentially-life threatening complications (PLTC, ie, diseaseand intervention-criteria) and life-treatening complications (LTC, ie, MNM, organ dysfunction criteria) according to the WHO near-miss approach [2]. Per Surinamese Maternal Mortality Committee consensus directions, the criteria were minorly, contexually adaptated to clarify definitions and prevent inclusion of women without PLTC (Table 1), as follows: 
Table 1. Definition of potentially life-threatening and life-threatening complications in pregnancy defined by WHO and minor adaptations within the Suriname Obstetric Surveillance System (SurOSS)
CRITERION
WhO
SUROSS

\section{Potentially life-threatening complications (PLTC)}

Disease-based criteria:

Severe post-partum Genital bleeding after delivery, with at $\bullet 1000 \mathrm{~mL}$ blood loss and/or

hemorrhage least one of the following: perceived ab- Any bleeding (antepartum, intrapartum or postpartum) with hypotension normal bleeding (1000 $\mathrm{mL}$ or more) or or transfusion of at least 3 products

any bleeding with hypotension or blood

transfusion

Severe pre-eclampsia Persistent systolic blood pressure of 160 Systolic blood pressure of $160 \mathrm{~mm} \mathrm{Hg}$ or more, or diastolic blood pressure of $\mathrm{mm} \mathrm{Hg}$ or more or a diastolic blood pres- $110 \mathrm{~mm} \mathrm{Hg}$ or more on two occasions at least $4 \mathrm{~h}$ apart and:

sure of $110 \mathrm{~mm} \mathrm{Hg}$; proteinuria of $5 \mathrm{~g}$ or - Thrombocytopenia (platelet count of $<100 \times 910^{\circ} / \mathrm{L}$ )

more in $24 \mathrm{~h}$; oliguria of $<400 \mathrm{~mL}$ in $24 \mathrm{~h}$; - Raised plasma ALT or AST (twice the upper limit of normal)

and HELLP syndrome or pulmonary oede- - Renal insufficiency (doubling of the serum creatinine)

ma. Excludes eclampsia. $\quad$ Pulmonary edema

- Pre-eclampsia complaints, not attributed to other causes, such as unresponsive headache, epigastric pain, visual disturbances

Eclampsia Generalized fits in a patient without previ- Seizures in a woman during pregnancy or up to $14 \mathrm{~d}$ postpartum, without any ous history of epilepsy. Includes coma in other attributable cause, with at least one of the following signs: pre-eclampsia.

- Hypertension ( $\geq 140 \mathrm{~mm} \mathrm{Hg}$ systolic or $\geq 90 \mathrm{~mm} \mathrm{Hg}$ diastolic)

- Proteinuria [at least $1 \mathrm{~g} / \mathrm{L}[$ [ $2+$ '] on dipstick testing]

- Thrombocytopenia (platelet count of $<100 \times 910 \%$ )

- Raised plasma ALT or AST (twice the upper limit of normal)

Severe sepsis

Presence of fever (body temperature Any pregnant or recently pregnant woman (up to 6 weeks postpartum) diag$>38^{\circ} \mathrm{C}$ ), a confirmed or suspected infec- nosed with severe sepsis (irrespective of the source of infection). Clinical diagtion (eg, chorioamnionitis, septic abor- nosis of severe sepsis, associated with two or more of the following: tion, endometritis, pneumonia), and at - Temperature $>38 \mathrm{C}$ or $<36 \mathrm{C}$ measured on two occasions at least $4 \mathrm{~h}$ apart least one of the following: heart rate $>90, \cdot$ Heart rate $>100$ beats/min measured on two occasions at least $4 \mathrm{~h}$ apart respiratory rate $>20$, leukopenia (white $\operatorname{e}$ Respiratory rate $>20 /$ min measured on two occasions at least $4 \mathrm{~h}$ apart blood cells $<4000$ ), leukocytosis (white - White cell count $>17 \times 10^{9} / \mathrm{L}$ or $<4 \times 10^{9} / \mathrm{L}$ or with blood cells $>12$ 000).

$\bullet>10 \%$ immature band forms, measured on 2 occasions

\begin{tabular}{|c|c|c|}
\hline Ruptured uterus & $\begin{array}{l}\text { Rupture of uterus during labour con- } \\
\text { firmed by laparotomy. }\end{array}$ & A visually confirmed, complete rupture of the myometrium and serosa \\
\hline $\begin{array}{l}\text { Severe complications of } \\
\text { abortion }\end{array}$ & Not further defined & $\begin{array}{l}\text { Severe hemorrhage ( } \geq 1000 \mathrm{~mL} \text {, hypotension, blood transfusion of at least } 3 \\
\text { products), severe sepsis or complications due lesion of intestines or other or- } \\
\text { gans or complications related to anesthesia. }\end{array}$ \\
\hline \multicolumn{3}{|l|}{ Intervention-criteria: } \\
\hline $\begin{array}{l}\text { Intensive care unit } \\
\text { admission }\end{array}$ & Not further defined & $\begin{array}{l}\text { Admission to a ward where mechanical ventilation and administration of con- } \\
\text { tinous vasoactive drugs are possible }\end{array}$ \\
\hline Intervention radiology & Not further defined & Not available in Suriname \\
\hline $\begin{array}{l}\text { Laparotomy excluding } \\
\text { caesarean section }\end{array}$ & Not further defined & $\begin{array}{l}\text { Excluding uncomplicated laparotomy for ectopic pregnancy when patient re- } \\
\text { mains hemodynamically stable and blood loss is less than } 1000 \mathrm{~mL} \text { and less } \\
\text { than three blood products }\end{array}$ \\
\hline \multirow[t]{2}{*}{ Use of blood products } & \multirow[t]{2}{*}{ Not further defined } & Use of at least 3 blood products \\
\hline & & Excluding blood transfusion for anaemia without any other complications \\
\hline \multicolumn{3}{|l|}{ Life-threatening } \\
\hline \multicolumn{3}{|l|}{ Organ-dysfunction criteria: } \\
\hline Cardiovascular & \multicolumn{2}{|c|}{$\begin{array}{l}\text { Shock, cardiac arrest (absence of pulse/ heart beat and loss of consciousness), use of continuous vasoactive drugs, cardio- } \\
\text { pulmonary resuscitation, severe hypoperfusion (lactate }>5 \mathrm{mmol} / \mathrm{L} \text { or }>45 \mathrm{mg} / \mathrm{dL} \text { ), severe acidosis }(\mathrm{pH}<7.1 \text { ) }\end{array}$} \\
\hline Respiratory & \multicolumn{2}{|c|}{$\begin{array}{l}\text { Acute cyanosis, gasping, severe tachypnea (respiratory rate }>40 \text { breaths per minute), severe bradypnea (respiratory rate } \\
<6 \text { breaths per minute), intubation and ventilation not related to anesthesia, severe hypoxemia (O2 saturation }<90 \% \text { for } \\
\geq 60 \text { min or } \mathrm{PAO} 2 / \mathrm{FiO}_{2}<200 \text { ) }\end{array}$} \\
\hline Renal & \multicolumn{2}{|c|}{$\begin{array}{l}\text { Oliguria non-responsive to fluids or diuretics, dialysis for acute renal failure, severe acute azotemia (creatinine } \geq 300 \mu \mathrm{mol} / \\
\mathrm{mL} \text { or } \geq 3.5 \mathrm{mg} / \mathrm{dL} \text { ) }\end{array}$} \\
\hline $\begin{array}{l}\text { Coagulation / } \\
\text { hematological }\end{array}$ & \multirow{2}{*}{\multicolumn{2}{|c|}{$\begin{array}{l}\text { Failure to form clots, massive transfusion of blood or red cells ( } 25 \text { units), severe acute thrombocytopenia ( }<50000 \text { plate- } \\
\text { lets } / \mathrm{mL} \text { ) }\end{array}$}} \\
\hline Hepatic & & \\
\hline Neurologic & \multicolumn{2}{|c|}{$\begin{array}{l}\text { Prolonged unconsciousness (lasting } \geq 12 \mathrm{~h} \text { )/coma (including metabolic coma), stroke, uncontrollable fits/status epilepti- } \\
\text { cus, total paralysis }\end{array}$} \\
\hline Uterine dysfunction & \multicolumn{2}{|c|}{ Uterine hemorrhage or infection leading to hysterectomy } \\
\hline
\end{tabular}


1. Transfusion of one blood product was increased to $\geq$ three blood products and women were excluded who were transfused for only anaemia without any other complications;

2. Laparotomy for ectopic pregnancy was only included if blood loss was $\geq 1000 \mathrm{~mL}$, blood was transfused or if patient was hemodynamically unstable [12];

3. Definition of maternal sepsis and eclampsia were harmonized with the United Kingdom (UKOSS) and International Network of Obstetric Surveillance System (INOSS) $[17,18]$.

\section{Data collection}

Eligible women were identified by the research coordinator (doctor) of each hospital during daily rounds. The authors weekly screened the medical files of all discharged women on the gynaecology and obstetric wards, in the intensive care of all hospitals. Additionally, the hospital registries reported whether patients on non-obstetric departments were consulted by a gynaecologist or obstetrician or had a ICD-code related to pregnancy. The research coordinator of the primary health care centers were contacted every quartile and reported women who were not transferred to a hospital.

Medical files were retrieved of all discharged women with PLTC and digitalized using an anonymous 188-item digital case report form on a password-secured Kobotoolbox. Data on demographics, general and obstetric history, occurrence of maternal and perinatal adverse outcomes were retrieved. The Surinamese Maternal Mortality Committee conducted verbal autopsy and audits of all maternal deaths and shared the elaborate case summaries.

For the purpose of this study, all maternal deaths in the study period and women with any WHOMNM, Namibian-MNM or SSA-MNM were extracted for analysis (Table 2). The SSA-MNM criteria were developed after our study commenced [10]. This resulted in women who received two units of red blood cells without any other MNM-criteria not being included.

We used hospital births (86\% of total births in Suriname) as a reference group. Data were collected through the childbirth books of all hospitals of babies with birth weight of at least $500 \mathrm{~g}$.

\section{Outcome measures}

The prevalence was calculated per 1000 live births and mortality-index was calculated by dividing maternal deaths (MD) with (MD+MNM). Causes were classified according to the International Classification of Diseases Maternal Mortality (ICD-MM) [19]. The underlying cause of maternal deaths and MNM diagnosis was the primary event in the chain-of-events [19,20]. Risk indicators were analyzed by comparing women who gave birth with MNM (numerator) to those who gave birth without MNM (denominator). No sample size calculation was performed due to the descriptive character of this study.

\section{Statistical analysis}

SPSS version 25 (IBM, Armonk, NY, USA) was used and simple descriptive statistics were performed (frequencies, proportions, bar charts and pie charts). No data imputation was conducted as missing data was $<5 \%$ and completely at random. Univariate binary logistic regression was performed to assess factors associated with MNM, reported in crude odds ratio (OR) with 95\% confidence intervals (95\% CI). Multivariate logistic regression included variables with $P<0.1$ in the univariate analysis and the hypothesis-driven variables age, parity and ethnicity, and was reported in adjusted OR (aOR, 95\% $\mathrm{CI}$ ). Maternal near-miss was the dependent variable for the association with maternal characteristics. Each adverse perinatal outcome (preterm birth, low birth weight, low Apgar score and stillbirth) was the dependent variable for the associon with maternal-near miss. Possible explanatory factors such as BMI, socio-economic status and medical history could not be included due to the lack of this data in the reference group. The risk of MNM related to cesarean section (CS) could not be studied, due to bias by indication (CS could be both the cause and result of MNM).

\section{Ethical considerations}

This research was approved by the ethical review board of the Surinamese Committee on Research Involving Human Subjects (\#VG21-16) on October 4th, 2016. Informed consent was not deemed necessary as data were obtained from medical records without identification of the woman. 
Table 2. MNM criteria according to the WHO, Namibian and Sub-Sahara Africa tools

\begin{tabular}{|c|c|c|c|c|c|c|c|}
\hline & WHO & Namibian & SSA & & WHO & Namibian & SSA \\
\hline Clinical criteria & & & & Cardiovascular dysfunction & & & \\
\hline Acute cyanosis & Yes & Yes & Yes & Shock & Yes & Yes & Yes \\
\hline Gasping & Yes & Yes & Yes & Cardiac Arrest & Yes & Yes & Yes \\
\hline Respiratory rate $>40$ or $<6 / \mathrm{min}$ & Yes & Yes & Yes & Use of continuous vasoactive drugs & Yes & Yes & No \\
\hline Shock & Yes & Yes & Yes & Cardiopulmonary resuscitation & Yes & Yes & Yes \\
\hline Oliguria non responsive to fluids or diuretics & Yes & Yes & Yes & Lactate $>5 \mathrm{mmL} / \mathrm{L}$ & Yes & Yes & No \\
\hline Failure to form clots & Yes & Yes & Yes & $\mathrm{pH}<7.1$ & Yes & Yes & No \\
\hline Loss of consciousness lasting more than 12 hours & Yes & Yes & Yes & Respiratory dysfunction & & & \\
\hline Cardiac Arrest & Yes & Yes & Yes & Acute cyanosis & Yes & Yes & Yes \\
\hline Stroke & Yes & Yes & Yes & Gasping & Yes & Yes & Yes \\
\hline Uncontrollable fits / total paralysis & Yes & Yes & Yes & Respiratory rate $>40$ or $<6 / \mathrm{min}$ & Yes & Yes & Yes \\
\hline Jaundice in the presence of pre-eclampsia & Yes & Yes & Yes & Intubation/ventilation not related to anesthesia & Yes & Yes & Yes \\
\hline Eclampsia & No & Yes & Yes & Oxygen saturation $<90 \%$ for $>60 \mathrm{~min}$ & Yes & Yes & Yes \\
\hline Ruptured uterus & No & Yes & Yes & $\mathrm{PaO}_{2} / \mathrm{FiO} 2<200 \mathrm{~mm} \mathrm{Hg}$ & Yes & Yes & No \\
\hline Sepsis or severe systemic infection & No & No & Yes & Renal dysfunction & & & \\
\hline Pulmonary edema & No & No & Yes & Oliguria non responsive to fluids or diuretics & Yes & Yes & Yes \\
\hline Severe complications of abortion & No & No & Yes & Dialysis for acute renal failure & Yes & Yes & No \\
\hline Severe malaria & No & No & Yes & Creatinine $\geq 300 \mu \mathrm{mol} / \mathrm{L}$ or $\geq 3.5 \mathrm{mg} / \mathrm{dL}$ & Yes & Yes & Yes \\
\hline Severe pre-eclampsia with ICU admission & No & No & Yes & Coagulation/hematological dysfunction & & & \\
\hline Laboratory criteria & & & & Failure to form clots & Yes & Yes & Yes \\
\hline Oxygen saturation $<90 \%$ for $>60 \mathrm{~min}$ & Yes & Yes & Yes & Transfusion of ... units of blood or red cells & 5 & 4 & 2 \\
\hline $\mathrm{PaO}_{2} / \mathrm{FiO} 2<200 \mathrm{~mm} \mathrm{Hg}$ & Yes & Yes & No & Severe acute thrombocytopenia $(<50.000 / \mathrm{mL})$ & Yes & Yes & Yes \\
\hline Creatinine $\geq 300 \mu \mathrm{mol} / \mathrm{L}$ or $\geq 3.5 \mathrm{mg} / \mathrm{dL}$ & Yes & Yes & Yes & Hepatic dysfunction & & & \\
\hline Bilirubin $>100 \mu \mathrm{mol} / \mathrm{L}$ or $>6.0 \mathrm{mg} / \mathrm{dL}$ & Yes & Yes & No & Jaundice in the presence of pre-eclampsia & Yes & Yes & Yes \\
\hline $\mathrm{pH}<7.1$ & Yes & Yes & No & Bilirubin $>100 \mu \mathrm{mol} / \mathrm{L}$ or $>6.0 \mathrm{mg} / \mathrm{dL}$ & Yes & Yes & No \\
\hline Lactate $>5 \mathrm{mEq} / \mathrm{mL}$ & Yes & Yes & No & Neurological dysfunction & & & \\
\hline Acute thrombocytopenia ( $<50000$ platelets/mL) & Yes & Yes & Yes & Loss of consciousness lasting more than $12 \mathrm{~h}$ & Yes & Yes & Yes \\
\hline Loss of consciousness, glucose/ketoacids in urine & Yes & Yes & Yes & Loss of consciousness, glucose/ketoacids in urine & Yes & Yes & Yes \\
\hline Management-based criteria & & & & Stroke & Yes & Yes & Yes \\
\hline Use of continuous vasoactive drugs & Yes & Yes & No & Uncontrollable fits / total paralysis & Yes & Yes & Yes \\
\hline Hysterectomy following infection or hemorrhage & Yes & Yes & Yes & Uterine dysfunction & & & \\
\hline Transfusion of ... units of blood or red cells & 5 & 4 & 2 & Hysterectomy following infection or hemorrhage & Yes & Yes & Yes \\
\hline Intubation and ventilation not related to anesthesia & Yes & Yes & Yes & Additional parameters & & & \\
\hline Dialysis for acute renal failure & Yes & Yes & No & Eclampsia & No & Yes & Yes \\
\hline Cardiopulmonary resuscitation & Yes & Yes & Yes & Ruptured uterus & No & Yes & Yes \\
\hline Laparotomy other than CS & No & No & Yes & Sepsis or severe systemic infection & No & No & Yes \\
\hline \multirow[t]{6}{*}{ Laparotomy other than CS/ectopic pregnancy } & No & Yes & No & Pulmonary edema & No & No & Yes \\
\hline & & & & Severe complications of abortion & No & No & Yes \\
\hline & & & & Severe malaria & No & No & Yes \\
\hline & & & & Severe pre-eclampsia with ICU admission & No & No & Yes \\
\hline & & & & Laparotomy other than CS & No & No & Yes \\
\hline & & & & Laparotomy other than CS/ectopic pregnancy & No & Yes & No \\
\hline
\end{tabular}

MNM - maternal near-miss, WHO - World Health Organization, SSA - sub-Saharan Africa, Yes - Criterion according to the specified tool, No - Not a criterion according to the specified tool

\section{RESULTS}

\section{Prevalence, mortality-index and characteristics}

During the one-year study period, there were 9114 live births and ten maternal deaths, which results in an MMR 110 per 100000 live births. SurOSS identified 486 women with PLTC, of whom 234 had no MNM criteria (Figure 1). The primary health care centers reported ten women with PLTC who were not referred to a hospital, and none had MNM criteria. The WHO-tool identified 71 MNM (ratio 7.8 per 1000 LB, mortality-index 12\% ( $\mathrm{n}=10 / 81)$ ), the Namibian-tool identified 118 MNM (ratio 12.9 per $1000 \mathrm{LB}$, mortality-index 8\% (n=10/128)) and the SSA-tool 242 MNM (ratio 26.5 per 1000 LB, mortality-index 4\% (n=10/252)) (Table 3). Namibian and SSA-MNM identified all women with WHO-MNM. The three MNM-tools identified all maternal deaths. Patient characteristics are reported in Table 4. The proportion of women with MNM is highest in hospital I (34\%-40\% compared to $24 \%$ of total births), which is the only referral hospital. Women of Maroon-descent represent majority of MNM (37\%-45\%), while they account for 29\% of total births. 


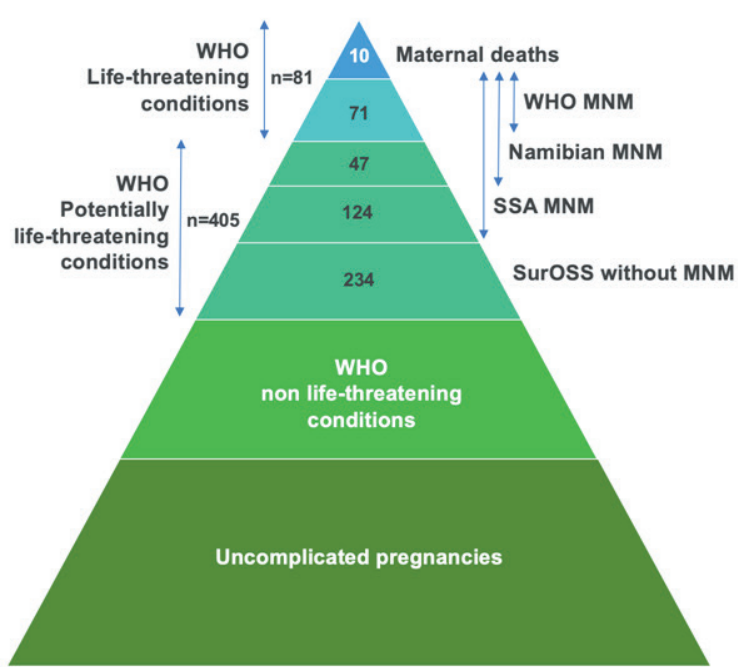

Figure 1. Number of women with maternal near miss according to the different tools.

\section{Differences between MNM criteria}

Figure 2 (and Table S1 and S2 in the Online Supplementary Document) presents the distribution of MNM events. Laboratory MNM-events played a small role in the SSA-tool ( $9 \%$, $\mathrm{n}=28 / 322)$ compared to WHO-tool $(28 \%, \mathrm{n}=31 / 109)$. The most important criteria were organ-dysfunction cardiovascular $(27 \%)$, coagulation $(27 \%)$ and respiratory $(20 \%)$ for WHOMNM, additional criteria (28\%), coagulation (25\%) and cardiovascular dysfunction (17\%) for Namibian and additional criteria (48\%) and coagulation dysfunction (32\%) for the SSA tool.

Transfusion of $>4$ red blood cell (RBC) products (Namibian-criteria), instead of the WHO threshold $>5$, led to an additional 10 cases of women without any WHO-MNM, while transfusion of $>2$ RBC (SSA-criteria) led to an additional 91 women without any WHO-MNM being included (Figure 3). The transfusion of blood products was responsible for $21 \%$ $(\mathrm{n}=15 / 71)$ of WHO-MNM, 26\% $(\mathrm{n}=31 / 118)$ of Namibian-MNM, and 46\% $(n=112 / 242)$ of SSA-MNM. Eclampsia was not considered a WHO-MNM in 80\% ( $\mathrm{n}=35 / 44)$ of cases as these women had no organ-dysfunction. Women with pre-eclampsia admitted to the ICU $(n=64)$ had no WHO-MNM criteria in 62\% ( $n=64 / 103)$.

Box 1 illustrates disputable case examples of:

(1) women who were included in SurOSS but did not meet any MNM-criteria;

(2) women included by Namibian- or SSA-MNM (not included by WHO-tool);

(3) women included solely by SSA-MNM (not included by WHO or Namibian-tool); and

(4) women with MNM in whom the severity of their disease is debatable.

Table 3. Demographics and maternal health indicators in Suriname

\begin{tabular}{|c|c|c|c|}
\hline & Number & & \\
\hline Deliveries & 9190 & & \\
\hline Total babies born & 9313 & & \\
\hline Live births & 9114 & & \\
\hline Maternal deaths & 10 & & \\
\hline Maternal mortality ratio* & 110 & & \\
\hline Near miss tools & WHO & Namibian & SSA \\
\hline Maternal near miss, $\mathrm{n}=$ & 71 & 118 & 242 \\
\hline MNM ratio $^{+}$ & 7.8 & 12.9 & 26.5 \\
\hline One MNM-criterion, $\mathrm{n}(\%)$ & $40(56 \%)$ & $79(67 \%)$ & $135(56 \%)$ \\
\hline Two or three MNM-criteria, n (\%) & $20(28 \%)$ & $26(22 \%)$ & $83(34 \%)$ \\
\hline Four or more MNM-criteria, n (\%) & $11(16 \%)$ & $13(11 \%)$ & $24(10 \%)$ \\
\hline Total amount of MNM-criteria & 146 & 218 & 458 \\
\hline Severe maternal outcomes, $\mathrm{n}$ & 81 & 128 & 252 \\
\hline 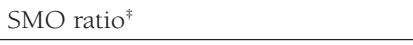 & 8.8 & 14.0 & 27.6 \\
\hline Maternal near miss: mortality ratio & 7: 1 & 12: 1 & 24: 1 \\
\hline Mortality index ${ }^{8}$ & $12.3 \%$ & $7.8 \%$ & $4.0 \%$ \\
\hline Severity score, mean (SD) & $2.5(2.2)$ & $2.1(2.0)$ & $2.1(1.8)$ \\
\hline
\end{tabular}

MNM - maternal near miss, WHO - World Health Organization, SSA sub-Saharan Africa, SD - standard deviation

* Maternal mortality ratio: maternal deaths per 100000 live births.

"Maternal near miss ratio: near miss cases per 1000 live births.

*Severe maternal outcome ratio: near miss cases and maternal deaths per 1000 live births.

${ }^{8}$ Mortality index: number of maternal deaths divided by number of women with severe maternal outcomes (near miss and maternal deaths), expressed in percentages

'Average number of severity markers (near-miss criteria) in all SMO cases.

\section{Underlying causes}

Hypertensive disorders of pregnancy (HDP) was the most frequent primary diagnosis in women with MNM (34\% WHO-MNM, 52\% Namibian-MNM) (Figure 4). The case fatality-rate for HDP was $17 \%(n=4 / 24$, WHO-MNM), $7 \%(n=4 / 61$, Namibian-MNM), and $4 \%$ $(n=4 / 97$, SSA-MNM). Women had multiple diagnosis in $8 \%-14 \%$, for example: severe pre-eclampsia and thrombocytopenia followed by massive hemorrhage. The primary diagnosis of this case would be HDP (Figure 4). In Figure S1 and S2 in the Online Supplementary Document all diagnoses are reported (in number of events) and its underlying causes. The low number of maternal deaths $(n=10)$ limited analysis of case fatality rates for the other diseases. However, 'other obstetric complications' and 'indirect, non-obstetric complications' are responsible for $60 \%(n=6 / 10)$ of maternal deaths, while they represent only $12 \%-17 \%$ of underlying causes of MNM (12\% Namibian- and SSA-MNM and 17\% WHOMNM).

\section{Factors associated with MNM}

For the WHO-criteria advanced maternal age and maroon ethnicity were associated with MNM, with respectively $\mathrm{aOR}=2.59(95 \% \mathrm{CI}=1.37-4.88)$ and $\mathrm{aOR}=2.04$ $(95 \% \mathrm{CI}=1.15-3.61)$ after adjustment for age, parity, and ethnicity (Table 5). For the Namibian-criteria only maroon ethnicity was associated with $\mathrm{MNM}, \mathrm{aOR}=1.93$ 
Table 4. Patient characteristics of women with MNM (not mutually exclusive) and all hospital births in the study period

\begin{tabular}{|c|c|c|c|c|c|c|c|c|}
\hline & \multicolumn{2}{|c|}{ WHO } & \multicolumn{2}{|c|}{ Namibian } & \multicolumn{2}{|c|}{ SSA } & \multicolumn{2}{|c|}{ HosPITAL BIRTHS } \\
\hline & $\mathrm{n}=71$ & $\%$ & $n=118$ & $\%$ & $\mathrm{n}=242$ & $\%$ & $\mathrm{n}=9190$ & $\%$ \\
\hline \multicolumn{9}{|l|}{ Hospital: } \\
\hline I & 24 & 33.8 & 47 & 39.8 & 81 & 33.5 & 2189 & 23.8 \\
\hline II & 24 & 33.8 & 31 & 26.3 & 62 & 25.6 & 2647 & 28.8 \\
\hline III & 15 & 21.1 & 24 & 20.3 & 58 & 24.0 & 2496 & 27.2 \\
\hline IV & 7 & 9.9 & 12 & 10.2 & 29 & 12.0 & 1481 & 16.1 \\
\hline $\mathrm{V}$ & 1 & 1.4 & 4 & 3.4 & 12 & 5.0 & 377 & 4.1 \\
\hline \multicolumn{9}{|l|}{ Age (years): } \\
\hline$<20$ & 8 & 11.3 & 16 & 13.6 & 31 & 12.8 & 1214 & 13.2 \\
\hline $20-35$ & 43 & 60.6 & 79 & 66.9 & 163 & 67.4 & 6807 & 74.1 \\
\hline$>35$ & 20 & 28.2 & 23 & 19.5 & 48 & 19.8 & 995 & 10.8 \\
\hline \multicolumn{9}{|l|}{ Parity: } \\
\hline Nullipara & 22 & 31.0 & 46 & 39.0 & 83 & 34.3 & 3151 & 34.3 \\
\hline $1-3$ & 34 & 47.9 & 50 & 42.4 & 110 & 45.5 & 4785 & 52.1 \\
\hline$\geq 4$ & 15 & 21.1 & 22 & 18.6 & 49 & 20.2 & 1221 & 13.3 \\
\hline Ethnicity: & & & & & & & \multicolumn{2}{|c|}{ Missing $n=43$} \\
\hline Maroon & 32 & 45.1 & 48 & 40.7 & 89 & 36.8 & 2639 & 28.9 \\
\hline Creole & 14 & 19.7 & 27 & 22.9 & 56 & 23.1 & 1993 & 21.8 \\
\hline Hindustani & 9 & 21.7 & 17 & 14.4 & 31 & 12.8 & 1737 & 19.0 \\
\hline Javanese & 6 & 8.5 & 8 & 6.8 & 18 & 7.4 & 943 & 10.3 \\
\hline Mixed & 7 & 9.9 & 10 & 8.5 & 27 & 11.2 & 1135 & 12.4 \\
\hline Indigenous & 2 & 2.8 & 5 & 4.2 & 12 & 5.0 & 348 & 3.8 \\
\hline Other & 1 & 1.4 & 3 & 2.5 & 9 & 3.7 & 352 & 3.8 \\
\hline Residency: & \multicolumn{2}{|c|}{ Missing $n=3$} & \multicolumn{2}{|c|}{ Missing $n=7$} & \multicolumn{2}{|c|}{ Missing $n=17$} & & \\
\hline Urban & 57 & 83.8 & 96 & 86.5 & 194 & 86.2 & - & - \\
\hline Coastal & 7 & 10.3 & 8 & 7.2 & 18 & 8.0 & - & - \\
\hline Rural & 4 & 5.6 & 7 & 6.3 & 13 & 5.8 & - & - \\
\hline Insurance: & \multicolumn{2}{|c|}{ Missing $n=1$} & \multicolumn{2}{|c|}{ Missing $n=3$} & \multicolumn{2}{|c|}{ Missing $n=5$} & & \\
\hline State & 49 & 70.0 & 79 & 68.7 & 167 & 70.5 & - & - \\
\hline Private & 14 & 20.0 & 25 & 21.7 & 52 & 21.9 & - & - \\
\hline None & 7 & 10.0 & 11 & 9.6 & 18 & 7.6 & - & - \\
\hline \multicolumn{9}{|l|}{ Gestational age: } \\
\hline$<22$ weeks & 9 & 12.7 & 13 & 11.0 & 25 & 10.2 & - & - \\
\hline 22-28 weeks & 3 & 4.2 & 5 & 4.2 & 16 & 6.6 & 160 & 1.7 \\
\hline 28-36 weeks & 30 & 42.3 & 52 & 44.1 & 89 & 36.8 & 1143 & 12.4 \\
\hline$\geq 37$ weeks & 29 & 40.8 & 48 & 40.7 & 112 & 46.3 & 7887 & 85.8 \\
\hline \multicolumn{9}{|l|}{ Pregnancy outcome: } \\
\hline Miscarriage & 7 & 9.9 & 10 & 8.5 & 20 & 8.3 & - & - \\
\hline Ectopic & 2 & 2.8 & 3 & 2.5 & 5 & 2.1 & - & - \\
\hline Vaginal delivery & 34 & 47.9 & 53 & 44.9 & 119 & 49.2 & 6904 & 75.1 \\
\hline Instrumental delivery & 1 & 1.4 & 2 & 1.7 & 2 & 0.8 & 123 & 1.3 \\
\hline Caesarean section & 27 & 38.0 & 50 & 42.4 & 96 & 39.7 & 2163 & 23.5 \\
\hline
\end{tabular}

(95\% CI = 1.25-2.99) after adjustment for age and parity (Table S3 in the Online Supplementary Document). For the SSA-criteria, next to advanced maternal age and maroon ethnicity, multiple pregnancy was significantly associated with MNM $(\mathrm{aOR}=3.38,95 \% \mathrm{CI}=1.68-6.81)$ (Table S4 in the Online Supplementary Document).

The stillbirth rate among women with WHO-MNM is $193 / 1000$ births ( $\mathrm{n}=11 / 57$ ), and 153/1000 births ( $n=15 / 98)$ and $110 / 1000$ births $(n=23 / 209)$ for respectively Namibian-and SSA-MNM. Women without MNM had a stillbirth rate of $12 / 1000$ births $(n=111 / 9123)$. Univariate analysis showed highly significant association between MNM and adverse perinatal outcomes (low birth weight, preterm birth, low Apgar score, and stillbirths) for the three MNM-criteria (Table 5, Table S3 and S4 in the Online Supplementary Document). In multivariate analysis only stillbirths remained significantly associated with MNM (WHO MNM: aOR=6.83, 95\%CI=2.96-15.76, Namibian-MNM: $\mathrm{aOR}=4.75,95 \% \mathrm{CI}=2.34-9.62$ and SSA-MNM: $\mathrm{aOR}=3.98,95 \% \mathrm{CI}=2.24-7.06$ ) after adjustment for age, parity, ethnicity, gestational age and birth weight. 


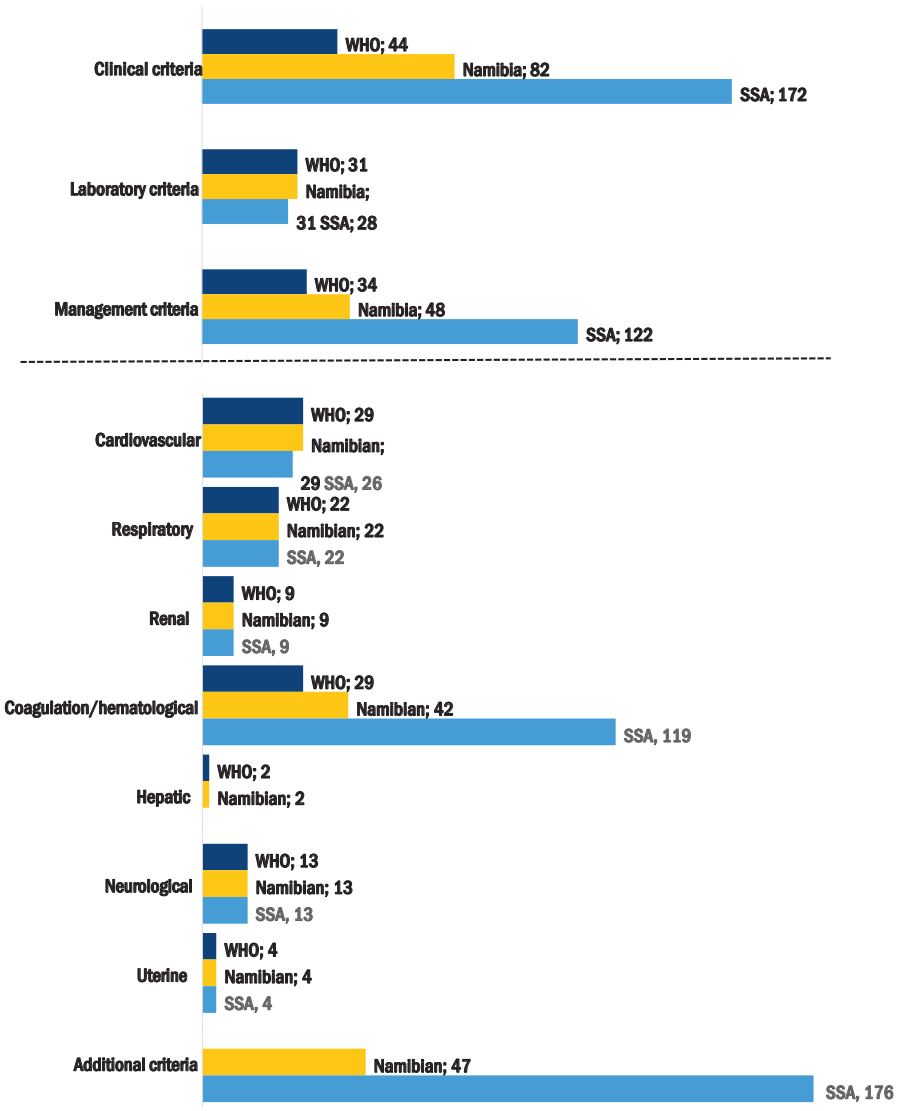

Figure 2. Number of women per maternal near miss category and tool, reported in events. *Coagulation dysfunction high for SSA-MNM and Namibian-MNM due to transfusion threshold of two units $(n=112)$ and four units $(n=31)$ respectively, instead of WHO-MNM threshold of five units of red blood cells $(n=15)$. †Additional criteria for Namibia-MNM included eclampsia $(n=44)$, uterine rupture $(n=1)$ and laparotomy other than for CS or ectopic pregnancy $(n=2)$. $¥$ Additional criteria for SSA-MNM included eclampsia $(n=44)$, uterine rupture $(n=1)$, severe sepsis $(n=40)$, pulmonary edema $(n=13)$, severe complications of abortion $(n=21)$, severe pre-eclampsia with ICU-admission $(n=103)$ and laparotomy other than CS $(n=6)$.

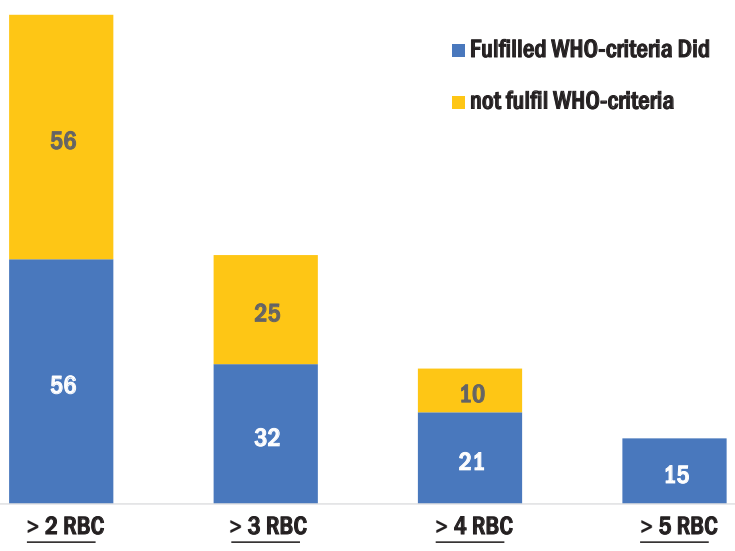

Figure 3. Number of women who received red blood cell (RBC) products and fulfilled WHO MNM-criteria.

\section{DISCUSSION}

This nationwide population-based study in Suriname demonstrated that for every woman who died, between seven and twenty-four women experienced MNM, depending on the type of MNM criteria used. The WHO-MNM criteria detected all maternal deaths and resulted in a mortality-index of $12 \%(n=10 / 71)$, which justified the WHO terminology life-threatening. However, WHO-criteria underestimate the prevalence of severe complications as certain disease-based complications such as eclampsia with a high case fatality rate are not included. Namibian-MNM (which included disease- and intervention) criteria led to more cases and a lower mortality-index (8\%, n=10/118). Application of the SSA-MNM (excluded the majority of laboratory-criteria and added several disease-based criteria) resulted in more cases and a lower mortality-index (4\%, n=10/242). SSA-MNM may have overestimated the prevalence of MNM since not all complications directly threatened the woman's life. For all three MNM tools, hypertensive disorders of pregnancy contributed most frequently to MNM. Advanced maternal age and maroon ethnicity were associated with MNM and women with MNM had six times the odds of a stillbirth. The absence of applicable and globally comparable MNM-criteria prevents countries such as Suriname from the sustainable implementation of MNM-registration.

\section{Maternal near-miss criteria and obstetric transition stages}

The fundamental aim of studying MNM is twofold: 1) to have globally comparable data on MNM and 2) to capture MNM cases and determine causes of MNM, which ultimately improve maternal health care and reduces maternal mortality [2]. The global universal WHO-MNM tool best achieves the first aim. Because MNM criteria are not as clear cut as other maternal health indicators (eg, MMR, stillbirth rate), underreporting is inevitable and will occur in all settings, most substantially in low-income settings [9$12,21,22]$. If the purpose is to find solutions for the most critical problems associated with severe maternal outcomes (the second fundamental aim), local adaptations are unavoidable, though this subverts the first aim of globally comparable data.

Contextually-tailored MNM criteria may be the answer to achieve both fundamental aims of uniformity and applicability of MNM criteria. One contextual approach could be to incorporate the 'obstetric transition framework', which assimilates context-specific analysis and recommendations to improve the quality 
Box 1. Case examples of women with and without a maternal near miss according to different criteria

\section{Severe morbidity according to SurOSS without any MNM criteria:}

1. Woman admitted with HELLP syndrome at 30 weeks of gestation, delivered a girl of 950 grams by CS who died two days later.

2. Woman had a severe post-partum psychosis post-partum, walked away and was never seen again.

3. ICU admission for severe hypokalemia (1.8 mEq/L) and rhabdomyolysis (CK 10000) due to pemba (clay) consumption.

4. Woman developed peri-partum cardiomyopathy three months post-partum and was admitted to ICU with moderate heart failure.

\section{Namibian- and SSA-MNM, not included by the WHO-criteria:}

5. A woman had three fits at home, was admitted with pre-eclampsia, stabilized and a caesarean section was performed. She had two fits post-partum.

6. A uterine rupture was discovered per-operatively in a woman with two previous CS. The woman received three packed cells and three fresh frozen plasma and was admitted to the ICU for severe hemorrhage (1500 mL). Her baby was in good condition.

7. Severe hemorrhage due to miscarriage at 19 weeks of gestation with hemoglobin level of $2.4 \mathrm{~g} / \mathrm{dL}$, for which patient was transfused 4 units RBC.

8. Laparotomy performed with suspicion for ectopic pregnancy, yet showed no ectopic mass. Post-operatively she developed a sepsis. Re-laparotomy showed an appendicitis and perforation of her intestines. An appendectomy and intestine repair were performed. Her pregnancy ended in a miscarriage.

\section{Additional SSA-MNM, not included by the WHO- or Namibian-criteria:}

9. Ruptured ectopic pregnancy, operated and complicated by a sepsis due to bilateral pneumonia for which she received intravenous antibiotics.

10. Severe pre-eclampsia, CS performed at 33 weeks. ICU admission for pulmonary edema (received 4-liter fluids in first 24 hour).

11. A woman from the interior with a septic and hemorrhagic miscarriage referred from interior clinic to hospital and arrived 12 hours later. She was admitted to the ICU, treated with intravenous antibiotics and was transfused 3 units of RBC.

12. Severe antepartum hemorrhage due to placental abruption at 36 weeks of gestation with vaginal birth of stillbirth baby. She was diagnosed with HELLP syndrome and transfused three units of RBC, six units of fresh frozen plasma and two platelet suspensions.

\section{MNM and debatable severity:}

13. Mild pre-eclampsia, uncomplicated term delivery with post-partum thrombocytopenia of 48000 (platelets $/ \mathrm{mL}$ ) which resolved spontaneously. (included by all MNM-tools).

14. Transfusion of two units of RBC for post-partum hemorrhage of $700 \mathrm{~mL}$ and pre-delivery hemoglobin level of $9.4 \mathrm{~g} / \mathrm{dL}$ (included by SSA MNM-tool).

15. Post-partum pre-eclampsia ICU-admission for monitoring of blood pressure and magnesium sulfate therapy. No complications (included by SSA MNM-tool).

16. In labor with fever, tachycardia with suspected chorioamnionitis for which antibiotics and CS. She recovered well (included by SSA MNM-tool).

of care [23]. The framework, developed by Souza et al. (2014), describes the transition from higher MMR/ fertility to low MMR/fertility within and between countries [23]. The problems and solutions for countries in obstetric transition stage I and II are incomparable to countries in stage III and IV. For example, in the first two stages, many maternal deaths occur and access to care and the availability of educated staff and resources play the most crucial role in reducing maternal mortality in these stages. Studying maternal mortality is of primary importance, and MNM studies play a limited role. However, if MNM studies are to be performed in these stages (eg, in rural settings with a low number of deaths), criteria should focus on 'direct' causes of maternal mortality (eg, severe hemorrhage and eclampsia). Stage III is known as a complicated stage as access to care is improved, and quality of care becomes a significant determinant of health outcomes. As maternal mortality decreases, MNM studies play an increasingly important role. The threshold of specific criteria (eg, blood transfusion) is higher than in stage I-II, and more focus is needed on 'indirect' causes. In stage IV, maternal mortality rates are low and severe outcomes are often the result of 'overmedicalization' and more high-risk pregnancies (high maternal age, non-communicable diseases, and pregnancies in women with severe comorbidities) [23]. MNM criteria in these stages need to focus on rare diseases with high case fatality rates (eg, abnormally invasive placentation, amniotic fluid embolism as proposed by the INOSS [18]), to reduce maternal mortality and reach the mostly aspirational stage V. 

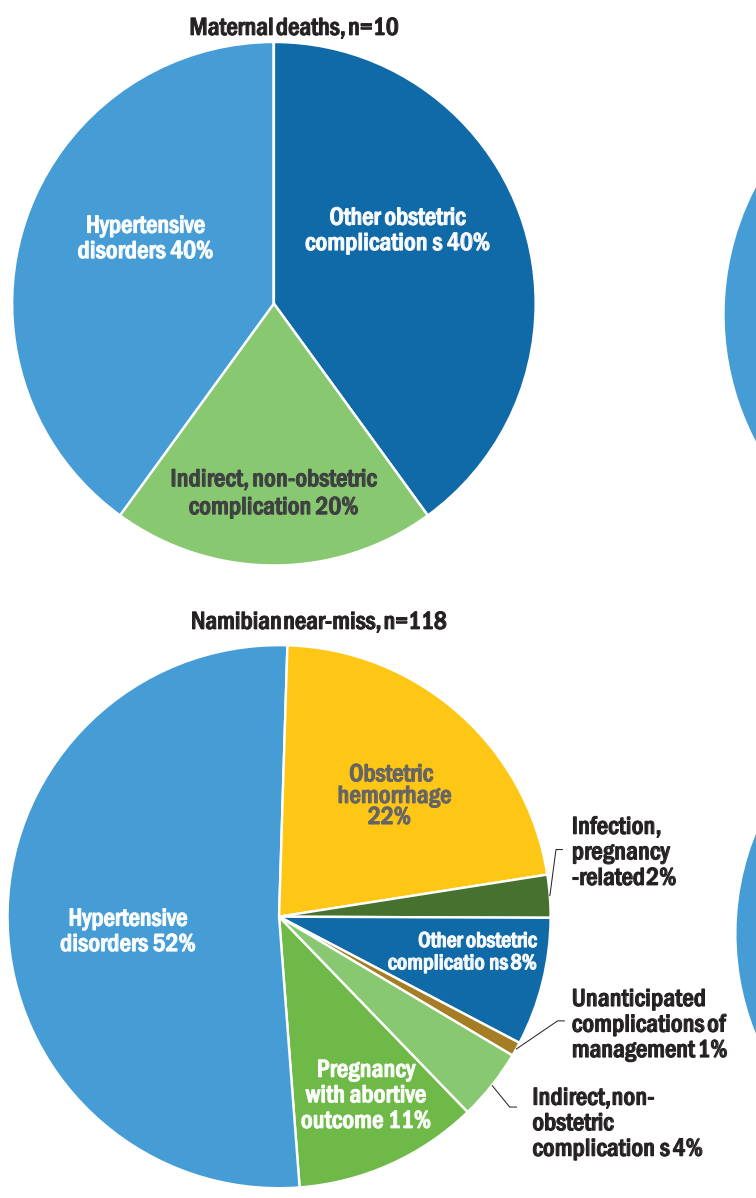

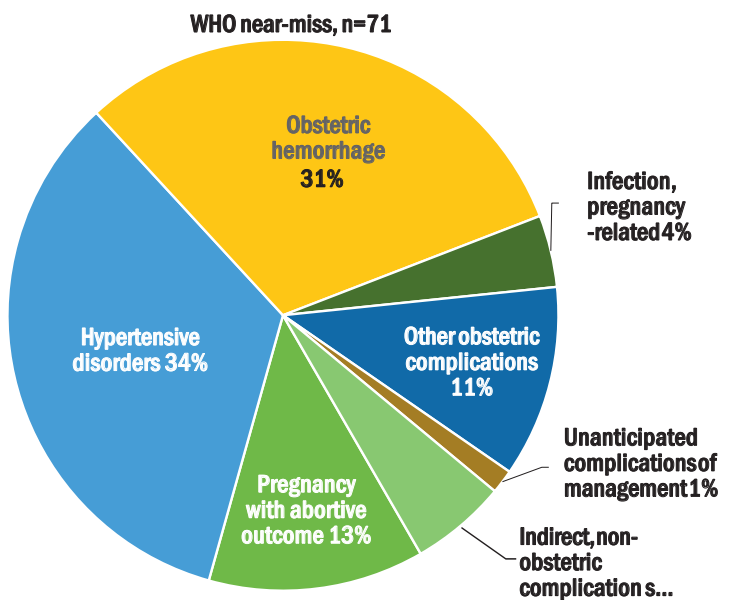

Sub-SaharanAfricanear-miss, $n=242$

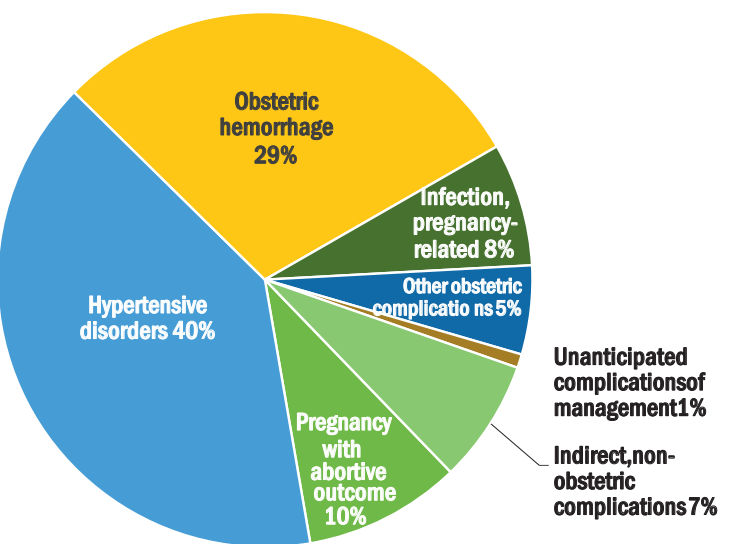

Figure 4. Primary underlying causes of maternal deaths and underlying diseases causing MNM according to the different tools. In the case of more than one near-miss event, the primary underlying cause was reported according to the ICD-MM guideline. *Maternal death "other obstetric complications" was caused by amniotic fluid embolism $(n=1)$, pulmonary embolism $(n=4)$ and peri-partum cardiomyopathy $(n=1)$.

Table 5. Association between WHO maternal near-miss and maternal characteristics and perinatal outcomes (MNM n=57, no MNM $\mathrm{n}=9123$ )

\begin{tabular}{|c|c|c|c|c|c|c|c|c|}
\hline & MNM* & No MNM & cOR & $95 \%$ CI & P-value & $A O R$ & $95 \%$ CI & $P_{\text {-value }}$ \\
\hline \multicolumn{9}{|l|}{ Maternal characteristics } \\
\hline Teenage pregnancy & $6 / 56(10.7 \%)$ & $1208 / 8950(13.5 \%)$ & 0.76 & $0.33-1.78$ & 0.529 & - & & \\
\hline Old maternal age $>35 \mathrm{y}$ & $15 / 56(26.8 \%)$ & $978 / 8950(10.9 \%)$ & 3.12 & $1.79-5.44$ & $<0.001$ & 2.59 & $1.37-4.88$ & 0.003 \\
\hline Maroon ethnicity & $27 / 56(48.2 \%)$ & $2608 / 9082(28.7 \%)$ & 2.31 & $1.37-3.91$ & 0.002 & 2.04 & $1.15-3.61$ & 0.015 \\
\hline Nullipara & $17 / 57(29.8 \%)$ & $3132 / 9091(34.5 \%)$ & 0.81 & $0.46-1.43$ & 0.464 & - & & \\
\hline Grande multipara $(\geq 4)$ & $16 / 57(28.1 \%)$ & $1203 / 9091(13.2 \%)$ & 2.56 & $1.43-4.57$ & 0.002 & 1.63 & $0.83-3.21$ & 0.158 \\
\hline Multiple pregnancy & $1 / 57(1.8 \%)$ & $120 / 9123(1.3 \%)$ & 1.34 & $0.18-9.76$ & 0.773 & - & & \\
\hline \multicolumn{9}{|l|}{ Perinatal outcomes } \\
\hline Low birth weight $(<2500 \mathrm{~g})$ & $27 / 55(49.1 \%)$ & $1299 / 9076(14.3 \%)$ & 5.77 & $3.39-9.83$ & $<0.001$ & $1.02^{*}$ & $0.41-2.57$ & 0.960 \\
\hline Preterm birth $(\mathrm{GA}<37 \mathrm{w})$ & $31 / 57(54.4 \%)$ & $1270 / 9123(13.9 \%)$ & 7.37 & $4.36-12.46$ & $<0.001$ & $2.65^{8}$ & $0.97-7.23$ & 0.058 \\
\hline Low Apgar 5 min below 7 & $6 / 43(14.0 \%)$ & $227 / 8850(2.6 \%)$ & 6.16 & $2.57-14.74$ & $<0.001$ & $2.45^{\prime}$ & $0.84-7.13$ & 0.100 \\
\hline Late stillbirth $(\mathrm{GA}>28 \mathrm{w})$ & $11 / 57(19.3 \%)$ & $111 / 9123(1.2 \%)$ & 19.42 & $9.80-38.47$ & $<0.001$ & $6.83^{\prime}$ & $2.96-15.76$ & $<0.001$ \\
\hline
\end{tabular}

GA - gestational age, MNM - maternal near miss, OR - odds ratio, CI - confidence interval, y - years, w - weeks, g - grams

* MNM is the dependent variable.

"MNM is the independent variable.

${ }^{\ddagger}$ Adjusted for age, parity ethnicity, gestational age, Apgar score and stillbirth.

${ }^{8}$ Adjusted for age, parity ethnicity, birth weight, Apgar score and stillbirth.

'Adjusted for age, parity, ethnicity, gestational age and birth weight. 


\section{Organ-based vs disease-based criteria}

Case identification is more feasible when using disease-based criteria, than organ-dysfunction criteria (25item list with many cut-off values) [2,17,24-26]. For example, clinicians easily identify a woman with eclampsia, while women with transient tachypnoea or thrombocytopenia are more difficult to identify. Another advantage of disease-based criteria is that the underlying problem is better understood and risk factors and case-fatality rates are easier to interpret. This makes it easier to identify gaps in the quality of care and find potential solutions to these problems. An illustrative example is the impact of disease-based criteria comparison between the Netherlands and the United Kingdom [24]. The observation that the Netherlands had a five-fold incidence of eclampsia, stemming from differences in clinical management, prompted rapid eclampsia incidence reductions through the implementation of different management protocols [25].

The WHO working group on Maternal Mortality and Morbidity Classification stated that organ dysfunction captures the severest diseases, and that disease-based criteria often have too low threshold to be considered 'severe' morbidity, and risk variation in definition and identification [6,7]. While organ-dysfunction are in the sequence of events leading from good health to death, it is not always measurable. An example is that only a small percentage of women with eclampsia in Suriname had measurable organ-dysfunction criteria, despite being very ill and nearly dead [26]. Although the inclusion threshold for near-miss is lower with most WHO disease-based criteria (eg, severe post-partum hemorrhage, sepsis and pre-eclampsia), it does not outweigh the benefits of clinical relevance and more feasible case identification. This would justify the initiation of a global consensus process for (higher threshold) definitions of severe morbidity and near-miss, as done by INOSS and the Core Outcomes in Women and Newborn (CROWN) Health initiative [18,27].

\section{Comparing prevalence and case-fatality rates}

When comparing the prevalence of WHO-MNM to the region, Suriname has a similar prevalence to Brazilian referral hospitals (9.4 per 1000 live births) [28]. No comparison with other Latin America/Caribbean countries is possible, as the studies are conducted in single sites, have limited case numbers, and have modified the criteria $[3,9,29]$. The lack of comparison possibilities emphasizes how crucial it is to apply uniform MNM criteria (as proposed by the WHO-tool) to report the prevalence of MNM in countries reliably.

The proportion of maternal deaths and WHO-MNM due to hypertensive disorders of pregnancy in Suriname was high, $40 \%$, and $34 \%$, respectively. HDP are known to contribute significantly to maternal deaths in Latin America (22\%), and for unclear reasons as the coverage of medication such as magnesium sulfate is adequate [4]. Currently, women with eclampsia are not included in MNM-criteria, while this disease is on the severest side of the spectrum of HDP. Only $80 \%$ of women with eclampsia in Suriname had WHO-MNM criteria, similar to previous studies [11,12]. Excluding eclampsia from MNM limits analysis of the factors contributing to the high burden of HDP. We are more likely to eliminate preventable maternal deaths if MNM studies were to include disease-based criteria with high case-fatality rates (such as eclampsia).

While MNM studies serve to monitor the quality of care by reporting numbers and trends, they barely facilitate the development of quality improvement strategies [3,8-12]. Near-miss audits are necessary to identify the lessons learned and to develop justified recommendations. The action and response to these findings and recommendations will finally reduce severe maternal (and perinatal) outcomes [25].

\section{Risk factors and adverse outcomes}

Identifying risk factors is vital to guide interventions to reduce severe maternal and perinatal outcomes. However, as maternal near-miss consists of different diseases in different proportions, risk factors can be challenging to interpret. For example, while post-partum hemorrhage is associated with grand multiparity, eclampsia is prevalent among younger nulliparous women [29-31]. If the proportion is similar, the net result might be no association between parity and maternal near-miss (including both post-partum hemorrhage and eclampsia), as seen in our study. Similarly, old maternal age is a well-known risk factor for a broad spectrum of obstetric complications [31] and is strongly correlated with MNM in our study, as well as in a large multi-country study [32]. However, if the proportion of eclampsia-related MNM increases (in Namibian-MNM), the association between maternal age and MNM disappears. Equivalent to previous studies in Suriname, women of Maroon descent are at increased risk of adverse pregnancy 
outcomes as they have twice the odds of MNM compared to women of other ethnicities (for all three tools) $[13,14]$. These ethnic disparities may reflect socioeconomic inequalities and inequity within the health care system and need more attention. Ethnic disparities in severe maternal outcomes have also been reported in Brazil [33] and high-income countries (eg, the United States, the Netherlands, and Germany) [34-36].

Although it is clear that complications leading to MNM also contribute to adverse perinatal outcomes, the magnitude and causes of perinatal deaths among women with MNM are mainly unknown in low- and middle-income countries. The stillbirth rate among women with WHO-MNM in Suriname (193/1000 births) is higher than reported in Brazil (140/1000 births) [37] or other Latin American countries (128/1000 births) [30], and lower than in low-resource settings (eg, Ethiopia 284/1000 births [38]). The higher stillbirth rate among women with WHO-criteria (than Namibian- or SSA-criteria) further confirms that the WHO-tool comprises of the most clinically severe criteria. Improving national data collection of childbirth outcomes, disaggregated for maternal conditions, is necessary to improve identification and quantify factors that contribute to maternal complications and adverse perinatal outcomes.

Finally, compared to solely MNM registration, an audit of maternal near-miss is more likely to identify shortfalls in clinical practice and lead to improvements in both maternal and perinatal outcomes.

While MNM-tools register the number of severe maternal outcomes, an audit is necessary to reveal the actual 'lessons to be learned' [39]. Recommendations can be formed through these 'lessons learned', which encourage targeted action and response (eg, guideline updates, enabling policies and legislation, conduct research to fulfil knowledge gaps). This cycle of continuous evaluation, 'maternal death and near-miss surveillance and response', is essential in the elimination of preventable severe maternal outcomes and deserves a more prominent place in MNM studies [39-41].

\section{Strengths and limitations}

Our study's strengths are the nationwide setting, prospective identification and robust data collection over a long period, and availability of background data on all deliveries. Several limitations need to be considered. First, we extracted data from patient records after discharge, and specific parameters (socioeconomic status, BMI) were unavailable. Second, reference data was limited to simple characteristics as no perinatal registry is yet in place and included no primary care and home births. Finally, we were not able to apply all SSA-criteria (eg, transfusion >2 RBC products) as SSA-criteria were published after the initiation of our study. The SSA-MNM prevalence is, therefore, higher than reported in our study.

\section{CONCLUSIONS}

The MNM-ratio in middle-income country Suriname is 8 per 1000 live births according to the WHOMNM tool. The Namibian- and SSA-MNM ratios are 13 and 27 per 1000 live birth. MNM may be underreported by the WHO (mortality-index 12\%) and overreported by Namibian- and SSA-MNM (mortality-index 8\% and 4\%). Solutions to prevent under- and overreporting without compromising comparability can be to (1) create context-specific MNM-criteria per obstetric transition stage and; (2) use disease-based criteria. Advanced maternal age and maroon ethnicity were associated with MNM and women with MNM had six times the odds of a stillbirth. While MNM allows identification of women with severe outcomes, an audit is necessary to identify shortfalls in clinical practice and reduce severe maternal and perinatal outcomes. 


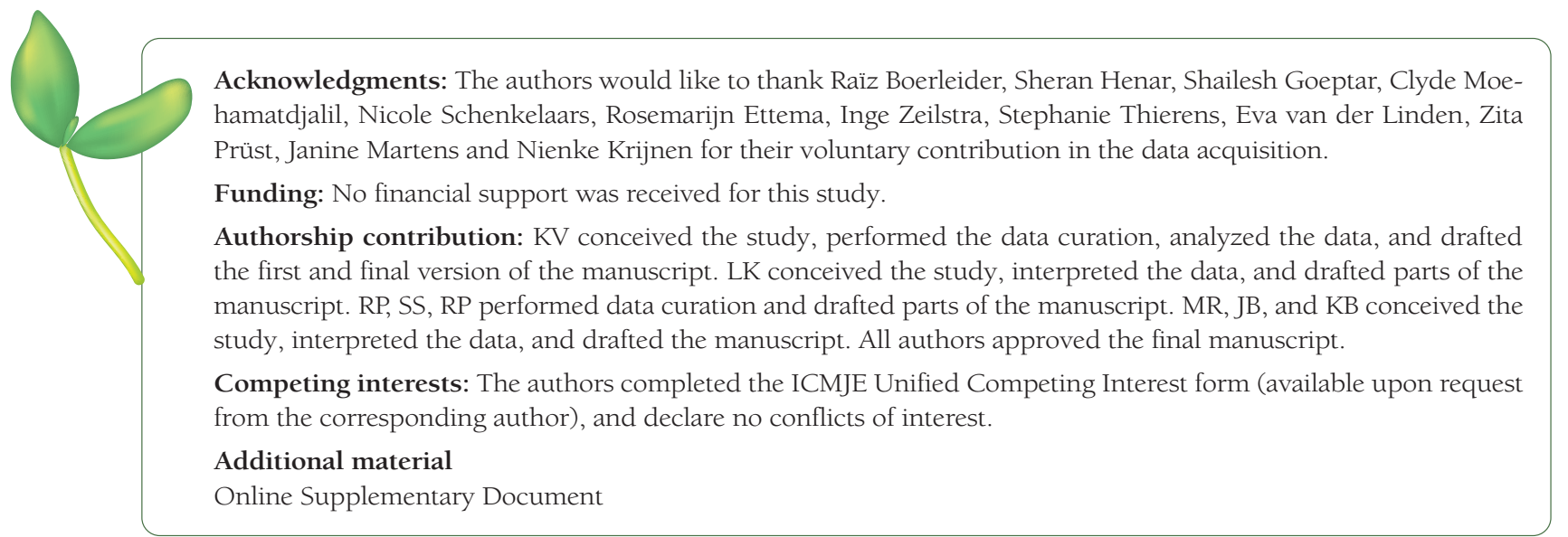

1 Alkema L, Chou D, Hogan D, Zhang S, Moller A-B, Gemmill A, et al. Global, regional, and national levels and trends in maternal mortality between 1990 and 2015, with scenario-based projections to 2030: a systematic analysis by the UN Maternal Mortality Estimation Inter-Agency Group. Lancet. 2016;387:462-74. Medline:26584737 doi:10.1016/S01406736(15)00838-7

2 World Health Organization. The WHO near-miss approach for maternal health - Evaluating the quality of care for severe pregnancy complications. World Health Organization. 2011. Available: https://apps.who.int/iris/bitstream/handle/10665/44692/9789241502221_eng.pdf?sequence=1. Accessed: 12 December 2019.

3 Geller SE, Koch AR, Garland CE, MacDonald EJ, Storey F, Lawton B. A global view of severe maternal morbidity: Moving beyond maternal mortality. Reprod Health. 2018;15:98. Medline:29945657 doi:10.1186/s12978-018-0527-2

4 Say L, Chou D, Gemmill A, Tunçalp Ö, Moller A-B, Daniels J, et al. Global causes of maternal death: A WHO systematic analysis. Lancet Glob Health. 2014;2:e323-33. Medline:25103301 doi:10.1016/S2214-109X(14)70227-X

5 Kodan LR, Verschueren KJC, van Roosmalen J, Kanhai HHH, Bloemenkamp KWM. Maternal mortality audit in Suriname between 2010 and 2014, a reproductive age mortality survey. BMC Pregnancy Childbirth. 2017;17:275. Medline:28851302 doi:10.1186/s12884-017-1466-6

6 Say L, Souza JP, Pattison RC. WHO working group on Maternal Mortality and Morbidity classifications. Maternal near miss-towards a standard tool for monitoring quality of maternal health care. Best Pract Res Clin Obstet Gynaecol. 2009;23:287-96. Medline:19303368 doi:10.1016/j.bpobgyn.2009.01.007

7 Pattinson R, Say L, Souza JP. WHO working group on Maternal Mortality and Morbidity classifications. WHO maternal death and near miss classifications. Bull World Health Organ. 2009;87:734. Medline:19876533 doi:10.2471/ BLT.09.071001

8 Witteveen T, de Koning I, Bezstarosti H, van den Akker T, van Roosmalen J, Bloemenkamp KW. Validating the WHO Maternal Near Miss Tool in a high-income country. Acta Obstet Gynecol Scand. 2016;95:106-11. Medline:26456014 doi:10.1111/aogs.12793

9 Goldenberg RL, Saleem S, Ali S, Moore JL, Lokangako A, Tshefu A, et al. Maternal near miss in low-resource areas. Int J Gynaecol Obstet. 2017;138:347-55. Medline:28513837 doi:10.1002/ijgo.12219

10 Tura AK, Stekelenburg J, Scherjon SA, Zwart JJ, van den Akker T, van Roosmalen J, et al. Adaptation of the WHO maternal near miss tool for use in sub-Saharan Africa: An International Delphi study. BMC Pregnancy Childbirth. 2017;17:445. Medline:29284433 doi:10.1186/s12884-017-1640-x

11 Tura AK, Zwart JJ, Van Roosmalen J, Stekelenburg J, van den Akker T, Scherjon S. Severe maternal outcomes in eastern Ethiopia: Application of the adapted maternal near miss tool. PLoS One. 2018;13:e0207350. Medline:30427926 doi:10.1371/journal.pone.0207350

12 Heemelaar S, Kabongo L, Ithindi T, Luboya C, Munetsi F, Bauer A-K, et al. Measuring maternal near-miss in a middle-income country: assessing the use of WHO and sub-Saharan Africa maternal near-miss criteria in Namibia. Glob Health Action. 2019;12:1646036. Medline:31405363 doi:10.1080/16549716.2019.1646036

13 Verschueren KJC, Prüst ZD, Paidin RR, Kodan LR, Bloemenkamp KWM, Rijken MJ, et al. Childbirth outcome and ethnic disparities in Suriname: a nationwide registry-based study in a middle-income country. Reprod Health. 2020;17:62. Medline:32381099 doi:10.1186/s12978-020-0902-7

14 Prüst ZD, Verschueren KJC, Bhikha-kori GAA, Kodan LR, Bloemenkamp KWM, Browne JL, et al. Investigation of stillbirth causes in Suriname: application of the WHO ICD-PM to national-level hospital data. Global Health Action. 2020;13:1794105. Medline:32777997 doi:10.1080/16549716.2020.1794105

15 Ministry of Social Affairs and Public Housing UNCF. Suriname Multiple Indicator Cluster Survey (MICS). 2018. Available: https://microdata.worldbank.org/index.php/catalog/3531/download/47198. Accessed: 12 December 2019.

16 Verschueren KJC, Kodan LR, Brinkman TK, Paidin RR, Henar SS, Kanhai HHH, et al. Bottom-up development of national obstetric guidelines in middle-income country Suriname. BMC Health Serv Res. 2019;19:651. Medline:31500615 doi:10.1186/s12913-019-4377-6

17 Mohamed-Ahmed O, Nair M, Acosta C, Kurinczuk JJ, Knight M. Progression from severe sepsis in pregnancy to death: a UK population-based case-control analysis. BJOG. 2015;122:1506-15. Medline:26213333 doi:10.1111/14710528.13551 
18 Schaap T, Bloemenkamp KWM, Deneux-Tharaux C, Knight M, Langhoff-Roos J, Sullivan E, et al. Defining definitions: a Delphi study to develop a core outcome set for conditions of severe maternal morbidity. BJOG. 2019;126:394-401. Medline:28755459 doi:10.1111/1471-0528.14833

19 World Health Organization. ICD-10 Application to deaths during pregnancy, childbirth and the puerperium 2012:77. Available: https://apps.who.int/iris/bitstream/handle/10665/70929/9789241548458_eng.pdf?sequence=1. Accessed: 17 December 2019.

20 van den Akker T, Bloemenkamp KWM, van Roosmalen J, Knight M. Classification of maternal deaths: where does the chain of events start? Lancet. 2017;390:922-3. Medline:28872018 doi:10.1016/S0140-6736(17)31633-1

21 Witteveen T, Bezstarosti H, de Koning I, Nelissen E, Bloemenkamp KW, van Roosmalen J, et al. Validating the WHO maternal near miss tool: comparing high- and low-resource settings. BMC Pregnancy Childbirth. 2017;17:194. Medline:28629394 doi:10.1186/s12884-017-1370-0

22 Tura AK, Trang TL, van den Akker T, van Roosmalen J, Scherjon S, Zwart JJ, et al. Applicability of the WHO maternal near miss tool in sub-Saharan Africa: A systematic review. BMC Pregnancy Childbirth. 2019;19:79. Medline:30808325 doi:10.1186/s12884-019-2225-7

23 Souza JP, Tunçalp Ö, Vogel J, Bohren M, Widmer M, Oladapo OT, et al. Obstetric transition: the pathway towards ending preventable maternal deaths. BJOG. 2014;121:1-4. Medline:24641529 doi:10.1111/1471-0528.12735

24 Schaap TP, Knight M, Zwart JJ, Kurinczuk JJ, Brocklehurst P, van Roosmalen J, et al. Eclampsia, a comparison within the international network of obstetric survey systems. BJOG. 2014;121:1521-8. Medline:24636369 doi:10.1111/14710528.12712

25 Schaap TP, van den Akker T, Zwart JJ, van Roosmalen J, Bloemenkamp KWM. A national surveillance approach to monitor incidence of eclampsia: The Netherlands Obstetric Surveillance System. Acta Obstet Gynecol Scand. 2019;98:34250. Medline:30346039 doi:10.1111/aogs.13493

26 Verschueren KJC, Paidin RR, Broekhuis A, Ramkhelawan O, Kodan LR, Kanhai HHH, et al. Why magnesium sulfate 'coverage' only is not enough to reduce eclampsia: lessons learned in a middle-income country. Pregnancy Hypertens. 2020;22:136-43. Medline:32979728 doi:10.1016/j.preghy.2020.09.006

27 Khan K. The CROWN Initiative: Journal editors invite researchers to develop core outcomes in women's health. Best Pract Res Clin Obstet Gynaecol. 2019;57:e1-4. Medline:25134450 doi:10.1016/j.bpobgyn.2014.06.002

28 Cecatti JG, Costa ML, Haddad SM, Parpinelli MA, Souza JP, Sousa MH, et al. Network for Surveillance of Severe Maternal Morbidity: a powerful national collaboration generating data on maternal health outcomes and care. BJOG. 2016;123:946-53. Medline:26412586 doi:10.1111/1471-0528.13614

29 Maswime S, Buchmann E. A systematic review of maternal near miss and mortality due to postpartum hemorrhage. Int J Gynaecol Obstet. 2017;137:1-7. Medline:28099749 doi:10.1002/ijgo.12096

30 De Mucio B, Abalos E, Cuesta C, Carroli G, Serruya S, Giordano D, et al. Maternal near miss and predictive ability of potentially life-threatening conditions at selected maternity hospitals in Latin America. Reprod Health. 2016;13:134. Medline:27814759 doi:10.1186/s12978-016-0250-9

31 Sheen JJ, Huang Y, Andrikopoulou M, Wright JD, Goffman D, D’Alton ME, et al. Maternal age and preeclampsia outcomes during delivery hospitalizations. Am J Perinatol. 2020;37:44-52. Medline:31430824 doi:10.1055/s-0039-1694794

32 Souza JP, Gülmezoglu AM, Vogel J, Carroli G, Lumbiganon P, Qureshi Z, et al. Moving beyond essential interventions for reduction of maternal mortality (the WHO Multicountry Survey on Maternal and Newborn Health): a cross-sectional study. Lancet. 2013;381:1747-55. Medline:23683641 doi:10.1016/S0140-6736(13)60686-8

33 Fernandes KG, Sousa MH, Cecatti JG. Skin Color and Maternal Near Miss: Exploring a Demographic and Health Survey in Brazil. Rev Bras Ginecol Obstet. 2017;39:209-16. Medline:28561138 doi:10.1055/s-0037-1603498

34 Reime B, Janssen PA, Farris L, Borde T, Hellmers C, Myezwa H, et al. Maternal near-miss among women with a migrant background in Germany. Acta Obstet Gynecol Scand. 2012;91:824-9. Medline:22404729 doi:10.1111/j.16000412.2012.01390.x

35 Wang E, Glazer KB, Howell EA, Janevic TM. Social Determinants of Pregnancy-Related Mortality and Morbidity in the United States: A Systematic. Obstet Gynecol. 2020;135:896-915. Medline:32168209 doi:10.1097/AOG.0000000000003762

36 Zwart JJ, Jonkers MD, Richters A, Ory F, Bloemenkamp KWM, Duvekot JJ, et al. Ethnic disparity in severe acute maternal morbidity: a nationwide cohort study in the Netherlands. Eur J Public Health. 2011;21:229-34. Medline:20522516 doi:10.1093/eurpub/ckq046

37 Zanardi DM, Parpinelli MA, Haddad SM, Costa ML, Sousa MH, Leite DFB, et al. Adverse perinatal outcomes are associated with severe maternal morbidity and mortality: evidence from a national multicentre cross-sectional study. Arch Gynecol Obstet. 2019;299:645-54. Medline:30539385 doi:10.1007/s00404-018-5004-1

38 Tura AK, Scherjon S, van Roosmalen J, Zwart JJ, Stekelenburg J, van den Akker T. Surviving mothers and lost babies burden of stillbirths and neonatal deaths among women with maternal near miss in eastern Ethiopia: a prospective cohort study. J Glob Health. 2020;10:01041310. Medline:32373341 doi:10.7189/jogh.10.010413

39 Kodan LK, Verschueren KJC, Boerstra GE, Gajadien I, Mohamed R, Bloemenkamp KWM. From passive surveillance to response: Suriname's steady efforts to implement Maternal Death Surveillance and Response (MDSR). 2020.Available: https://www.researchsquare.com/article/rs-35174/v1. Accessed: 12 October 2020.

40 Knight M, Lewis G, Acosta CD, Kurinczuk JJ. Maternal near-miss case reviews: the UK approach. BJOG. 2014;121:1126. Medline:25236644 doi:10.1111/1471-0528.12802

41 Schaap T. Severe maternal morbidity and mortality: The Netherlands Obstetric Surveillance System. PhD thesis, general discussion, p165-186. 2019. 